\title{
Congenital infiltrating lipoma of the upper limb in a patient with von Willebrand disease
}

\author{
J.M.Lasso, A.España,* M.I.Zudaire,t E.de Alava\# and A.Bazán
}

Departments of Plastic Surgery, *Dermatology, tGenetics and \#Pathology, University Clinic of Navarra, School of Medicine, University of Navarra, PO Box 4209, Pamplona 31080, Navarra, Spain

\section{SUMMARY}

Infiltrating lipoma is a rare variety of lipoma, characterized by an infiltration of the adipose tissue of the muscles. Infiltrating lipomas are usually classified in two groups: intermuscular infiltrating lipoma and intramuscular infiltrating lipoma. Most are acquired, and they usually appear in middle-aged individuals. Exceptionally, they are congenital. In such cases they are not related to other diseases. We report an 8-year-old boy with a congenital infiltrating lipoma of the upper limb and von Willebrand disease. Both diseases are linked to an alteration in chromosome 12, but this clinical association seems to be random rather than causal.

\section{KEY WORDS}

Chromosome 12, congenital lipoma, genetics, infiltrating lipoma, von Willebrand disease

Correspondence: Agustín España.

E-mail: aespana@unav.es 
Infiltrating lipomas are unusual, benign tumours derived from mature white fat cells; they are not capsulated, and have a tendency to infiltrate the muscle tissue and nerve fibres. They frequently relapse after surgical excision. ${ }^{1}$ They are usually acquired, and are mainly located in the head and neck, ${ }^{2-5}$ although other locations ${ }^{6-8}$ are described. Their presence at birth is rare. ${ }^{9-12}$ Some lipomas are related to specific chromosome disorders (chromosome 12q). ${ }^{13-15}$ Von Willebrand disease (VWD) is a disorder of the haemostatic system, characterized by a defect in a protein related to factor VIII. ${ }^{16}$ It has been associated with an alteration in chromosome $12 \mathrm{p} .{ }^{17}$ We present an 8-year-old boy with congenital infiltrating lipoma and VWD. However, the association of both unusual diseases is probably random rather than causal.

\section{CASE REPORT}

An 8-year-old boy was seen because of a tumour present since birth in the left shoulder and forearm. The parents reported that the child showed a slight loss of strength in that arm, without change in sensitivity. There was no relevant obstetric history, and the mother had not ingested any drug during pregnancy. There was no relevant family history. Examination showed a soft, painless mass, without inflammation, located in the deltoid area and measuring $10 \mathrm{~cm}$ at the base; the mass was in contact with deep structures. The tumour could be seen better when the patient contracted the muscle. The circumference of the left forearm was almost $3 \mathrm{~cm}$ greater than the other forearm, without inflammation and without epidermal disorders (Fig. 1). X-ray showed no bony abnormalities. Magnetic resonance imaging revealed a fatty tumour on the anterior and lateral aspects of the deltoid muscle, extending down to the elbow, but not compromising it. In addition, on the anterior aspect of the forearm there was another fatty tumour, extending distally to the wrist. This second tumour was dissecting the muscular groups, and some of them were atrophic. There were normal vessels inside the fat. An electromyograph showed an alteration of potentials in the abductor pollicis brevis muscle of the left hand. A biopsy of the fatty tumour showed mature adipose tissue infiltrating bundles of skeletal muscle. No atypia or mitoses of fat cells, nor multivacuolated lipoblasts or vascular channels, were observed. These findings were consistent with an infiltrating lipoma.

Routine preoperative clotting tests were abnormal, so detailed studies were performed. These revealed a bleeding time of 4 min $30 \mathrm{~s}$ (normal $<10 \mathrm{~s}$ ), prothrombin time $89 \%$ (normal > 75\%), kaolin-cephalin time $36 \mathrm{~s}$ (normal 25-35), fibrinogen $264 \mathrm{mg} \mathrm{dL}^{-1}$ (normal 200-500), thrombin time 14'4 s (normal 15-20), factor VIII 47\% (normal $100 \%$ ), von Willebrand factor antigen 100\% (normal 60-140\%) and ristocetin cofactor activity 50\% (normal 100\%); multimeric analysis of von Willebrand showed proportional reduction of von Willebrand multimeres, and normal multimeric structure, consistent with a type I VWD.

After treatment with desmopressin (DDAVP ${ }^{\circledR}$, Ferring) we proceeded to operate on the patient. Surgical removal of both tumours was performed under general anaesthesia. 
The tumour in the deltoid area was dissecting the fibres of the deltoid muscle, and the forearm lipoma was intermuscular. Two years later there was no evidence of tumour recurrence and the clotting status was unchanged from the preoperative analysis. The patient's father showed similar findings, suggesting that he also presents a VWD type I. We could not study the patient's mother.

\section{Cytogenetic analysis}

Tumour genetic analysis was performed by a cytogenetic procedure. ${ }^{18}$ After surgical removal, the sample was disaggregated enzymatically with collagenase, and the resulting cells were plated out in plastic flasks and cultured for 10 days. The cultures were harvested according to standard procedures. In the subsequent cytogenetic analysis, the clonality criteria and the description of karyotypes followed the recommendations of the International System for Human Cytogenetic Nomenclature. ${ }^{19}$ For comparative genomic hybridization (CGH) analysis, genomic DNA was extracted from blocks of paraffin-embedded material by proteinase $\mathrm{K}$ digestion. Tumour DNA was labelled with fluorescein isothiocyanate-dUTP and normal female reference DNA with Texas red-dUTP using a nick translation commercial kit (Vysis). Labelled tumour and normal DNAs, together with unlabelled Cot-1 DNA, were mixed and applied on male lymphocyte metaphase preparations. The CGH results were analysed with a PSI software package and average ratio profiles were determined from eight to 10 metaphases. We could not detect any genetic aberrations by either G-banding or CGH: the tumour cells presented a normal 46,XY karyotype and a normal CGH profile.

\section{DISCUSSION}

Fatty tumours are divided into three types depending on the cells from which they derive: lipoblastomas, hibernomas and lipomas, ${ }^{20}$ the last type being most frequent. Most of them are acquired. Infiltrating lipoma is a rare variety, characterized by the proliferation of non-capsulated mature fatty tissue which infiltrates the surrounding muscle in two ways: intermuscular or intramuscular. Intermuscular infiltrating lipomas are more frequent. ${ }^{1-5}$ Congenital infiltrating lipoma is an unusual type, and only four cases have been described, three of them affecting limbs, ${ }^{9-11}$ and one in the sacral area. ${ }^{12}$ Our patient had two infiltrating lipomas in one limb.

Congenital infiltrating lipoma must be distinguished from other congenital tumours that may appear in the first months of life. Lipoblastoma is a congenital tumour. It can appear from birth onwards, and is made up of adipoblasts. There are two types, one being deeply located and poorly circumscribed, and the other being more superficial and well circumscribed. ${ }^{9,21}$ Other tumours in the differential diagnosis are infiltrating angiolipoma, fibrosarcoma, rhabdomyosarcoma and sarcomas of the bones and cartilage. ${ }^{12}$ These are acquired, and the histological characteristics and clinical evolution 
differentiate these entities from congenital infiltrating lipoma. Treatment of infiltrating lipoma is by surgical excision, especially if nerve compression and muscular damage are present.

In our patient there was a simultaneous diagnosis of congenital infiltrating lipoma and VWD. VWD is an autosomal dominant inherited disease, related to chromosome 12p. ${ }^{16}$ In addition, since the initial cytogenetic characterization of lipomas in $1986,{ }^{22}$ several lipomas have been studied, mostly by conventional cytogenetics. Simple lipomas are known to be karyotypically heterogeneous, ${ }^{23}$ and different genetic subgroups have been characterized: those with normal karyotypes, those with 12q13-15 aberrations, 6p rearrangements, $13 q$ rearrangements, $8 q 11-13$ aberrations, ring or giant marker chromosomes or both, and other chromosomal abnormalities. Normal karyotypes are twice as frequent in tumours in patients under 30 years of age than in those from older individuals, and are the usual finding in cases of multiple lipoma. In our patient, we did not detect genetic aberrations by either G-banding or CGH: the tumour cells had a normal karyotype.

There are three possible reasons for this normal karyotype after cell culture: first, and most likely, is that our case belongs to the subgroup of karyotypically normal, multiple lipomas in young patients; second, that the cells described as normal are really neoplastic cells but with a submicroscopic alteration that we cannot detect at a chromosomal level, and third, that normal cells present in the tumour had a growth advantage over malignant cell clones, so we only detected the former. To eliminate the last possibility we decided to analyse the tumour by CGH (only one cytogenetic study by CGH of lipomatous tumours ${ }^{24}$ has been reported to date). We used archival paraffin tissue to select only the tumour cells present in the biopsy. Again, no aberrations were detected. As CGH can only detect DNA copy number changes, possible translocations or inversion may remain concealed using this technique.

The significance of cells with a normal karyotype in a neoplastic situation, whether or not they represent tumour cells, has been debated. In solid tumours, normal cells are usually considered to represent stromal and supporting elements. However, the karyotypically normal cells may represent truly neoplastic cells or mask a submicroscopic alteration. ${ }^{18}$ The presence of lipomas with no detectable chromosomal abnormalities also highlights the importance of a combined cytogenetic and molecular approach in a large series of tumours.

In conclusion, congenital infiltrating lipoma is an unusual clinical entity. Our patient represents the first case where two different congenital infiltrating lipomas are described, as he had both intermuscular and intramuscular types of infiltrating lipoma. In addition, in this particular case, we think that the association between congenital infiltrating lipoma and VWD was random and not causal. 


\section{REFERENCES}

1. Harrington AC, Adnot J, Chesser RS. Infiltrating lipomas of the upper extremities. J Dermatol Surg Oncol 1990; 16: 834-7.

2. Scherl MP, Som PM, Biller HF et al. Recurrent infiltrating lipoma of the head and neck. Case report and literature review. Arch Otolaryngol Head Neck Surg 1986; 112: 1210-12.

3. Garavaglia J, Gnepp DR. Intramuscular (infiltrating) lipoma of the tongue. Oral Surg Oral Pathol 1987; 63: 348-50.

4. Mattel SF, Persky MS. Infiltrating lipoma of the sternocleido-mastoid muscle. Laryngoscope 1983; 93: 205-7.

5. Grevers G, Ihrler S, Vogl $\mathrm{T}$ et al. Provocable tumor of the cheek as a manifestation of so-called infiltrating lipoma of the masseter muscle. Laryngorhinootologie 1992; 71: 328-31.

6. Vade A, Jeske J. Infiltrating lipoma of the chest wall. Pediatr Radiol 1993; 23: 469-70.

7. Kubota M, Nagasaki A, Ohgami H et al. An infantile case of infiltrating lipoma in the buttock. J Pediatr Surg 1991; 26: 230-2.

8. Dattolo RA, Nesbit GM, Kelly KE et al. Infiltrating intramuscular lipoma of the paraspinal muscles. Ann Otol Rhinol Laryngol 1995; 104: 582-4.

9. Al-Qattan MM, Weinberg M, Clarke HM. Two rapidly growing fatty tumors of the upper limb in children: lipoblastoma and infiltrating lipoma. J Hand Surg 1995; 20A: 20-3.

10. Adair FE, Pack GT, Farrior JH. Lipomas. Am J Cancer 1932; 16: 1104-20.

11. Oosthuizen SF, Berneison J. Two cases of lipomatosis involving bone. Br J Radiol 1947; 20: 426-32.

12. Winkler M, Petrelli N, Cohen A. Pediatric infiltrating lipomas: case report and review of the literature. J Surg Oncol 1987; 35: 59-62.

13. Nilbert M, Rydholm A, Mitelman F et al. Characterization of the 12q13-15 amplicon in soft tissue tumors. Cancer Genet Cytogenet 1995; 83: 32-6.

14. van de Ven WJM, Schoenmakers EFPM, Wanschura S et al. Molecular characterization of MAR, a multiple aberration region on human chromosome segments 12q13-q15 implicated in various solid tumors. Genes Chromosom Cancer 1995; 12: 296-303.

15. Sreekantaiah C, Leong SP, Fleming S et al. Translocation (2;6) (q36;p21.3) in a lipoma. Cancer Genet Cytogenet 1990; 45: 81-4.

16. Rodgers GM, Greenberg CS. Inherited coagulation disorders. In: Wintrobe's Clinical Hematology (Lee GR, Foerster J, Lukens J, Paraskevas F, Greer JP, Rodgers GM, eds), 10th edn. Baltimore: Williams \& Wilkins, 1998; 1682-732.

17. Ginsberg D, Sadler JE. Von Willebrand disease: a database of point mutations, insertions, and deletions. Thromb Haemost 1993; 69: 177-84.

18. Sandberg AA, Bridge JA. The Cytogenetics of Bone and Soft Tissue Tumors, 2nd edn. Heidelberg: Springer-Verlag, 1995. 
19. Mitelman F (ed.) ISCN: An International System for Human Cytogenetic Nomenclature. Basel: Karger, 1995.

20. Lever WF, Schaumburg-Lever G. Tumours of fatty, muscular and osseous tissue. In: Histopathology of the Skin, 6th edn. Philadelphia: Lippincott, 1983; 652-6.

21. Chung EB, Enzinger FM. Benign lipoblastomatosis. An analysis of 35 cases. Cancer 1973; 32: 482-92.

22. Heim S, Mandahl N, Kristoffersson U et al. Reciprocal translocation t(3;12) (q27;q13) in lipoma. Cancer Genet Cytogenet 1986; 23: 301-4.

23. Willen H, Akerman M, Dal Cin P et al. Comparison of chromosomal patterns with clinical features in 165 lipomas: a report of the CHAMP study group. Cancer Genet Cytogenet 1998; 102: 146-9.

24. Szymanska J, Virolainen M, Tarkkanen M et al. Overrepresentation of 1q21-23 and 12q13-21 in lipoma-like liposarcomas but not in benign lipomas: a comparative genomic hybridization study. Cancer Genet Cytogenet 1997; 99: 14-18. 


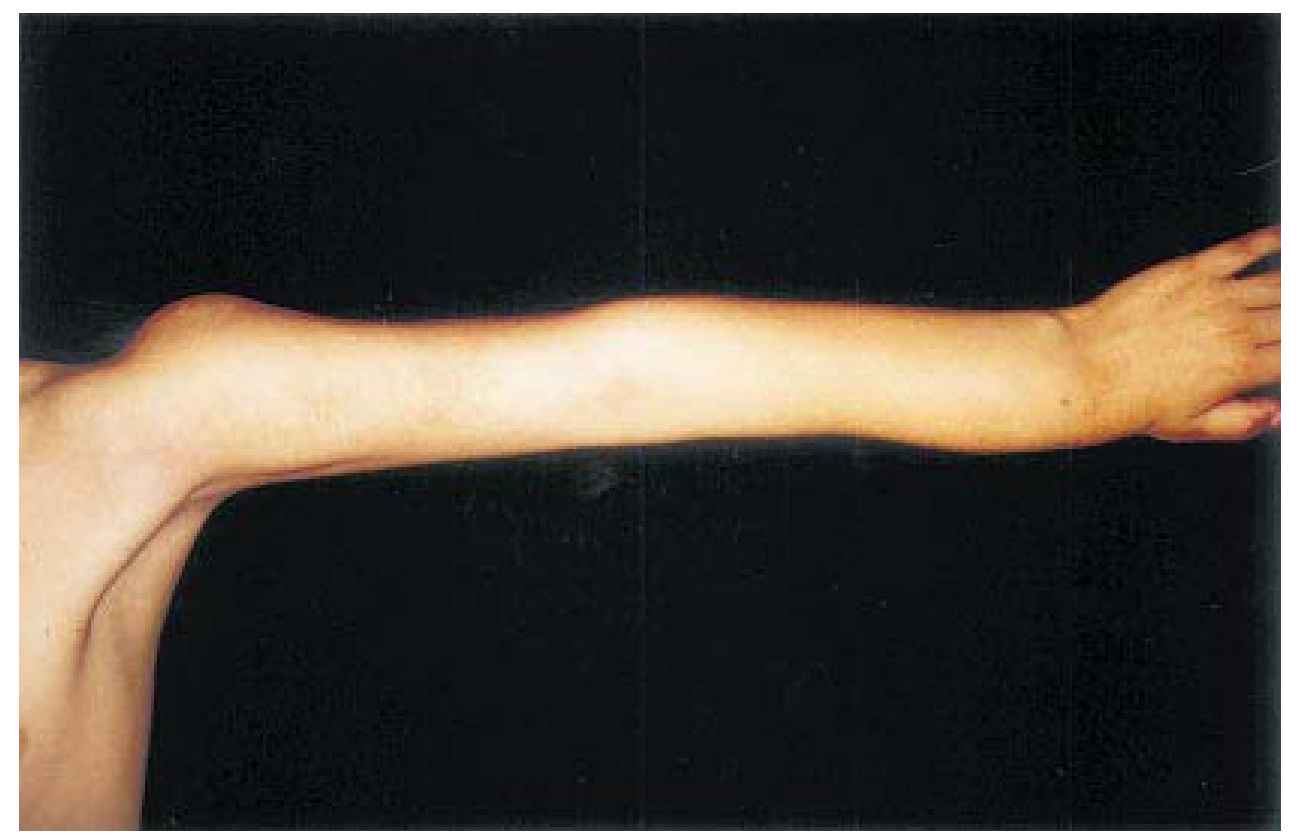

Figure 1. The tumour in the shoulder can be seen better when the patient contracts the muscle. There is a second tumour on the radial aspect of the left forearm, from the elbow to the wrist. The base of the thumb is also involved. 